Estudics de Género de El Colegio de México. 3(6) julio-diciembre de 2017. pp. 69-100 e-I.SSN 2395-9185

DOI: http//dx.doi.org/10.24201/eg.v3i6.142

Artículo

\title{
La violencia contra las mujeres y la crisis de derechos humanos:
}

de la narcoguerra a las guerras necropolíticas

Violence against women and the human rights crisis:

from the war on drugs to the necropolitical wars

\section{Ariadna Estévez}

Universidad Nacional Autónoma de México, Centro de Investigaciones sobre América del Norte (CISAN), email: aestevez@unam.mx

\section{Resumen}

El artículo argumenta que las organizaciones de derechos humanos y sus reportes tienden a ignorar las continuidades de género que hay en la violencia criminal que origina la crisis de derechos humanos. Desarrolla la idea de las guerras necropolíticas como un tipo de conflicto que simultáneamente explica la violencia delincuencial y la de género, como parte de un contínuum de una violencia cuyo objetivo es asegurar el comercio de la droga y la mercantilización de los cuerpos de las mujeres para afirmar los mercados criminales. Con México como estudio de caso, se ofrece una tipología de las guerras necropolíticas: la guerra por la gubernamentalización necropolítica del Estado y la guerra por la desposesión de los cuerpos de las mujeres. Mientras que estas dos guerras tienen objetivos diferentes - cooptar y reconfigurar al Estado, y desposeer a las mujeres de sus cuerpos, respectivamente- comparten una característica: un espacio socio-legal disfuncional, permanentemente corrupto $\mathrm{y}$ deliberadamente letal que asegura la impunidad de las tecnologías de muerte del necropoder: masacre, feminicidio y desaparición forzada. Al analizar la 
violencia desde la perspectiva de las guerras necropolíticas, la violencia contra las mujeres se vuelve visible.

Palabras clave: violencia sexual; feminicidio; desaparición forzada; desposesión; necropolítica

\begin{abstract}
The article contends that human rights organizations and their reports tend to dismiss the gender continuities of criminal violence in the human rights crisis. Consequently, it develops the idea of necropolitical wars as a type of conflict that simultaneously explains criminal and sexual violence as part of a contínuum of violence for the securing of criminal markets and the commodification of women's bodies. Using Mexico as a case study, it offers a typology of necropolitical wars: the war for the necropolitical governmentalization of the State and the war for the dispossession of women's bodies. While these wars have different aims - co-opting and reconfiguring the state, on the one hand; and dispossessing women of their bodies, on the other - they share a common feature: a dysfunctional, permanently corrupt and deliberately deadly legal-spatial site that secures the impunity of their power technologies: massacre, feminicide and forced disappearance. By analyzing violence through the lens of necropolitical wars, violence against women becomes clearly visible.
\end{abstract}

Key words: sexual violence; feminicide; forced disappearance; dispossession; necropolitics 


\section{Introducción}

Puesto de manera muy general, las mexicanas y mexicanos huyen del país porque existe una grave “crisis de derechos humanos”. El informe más reciente de derechos humanos en México (Open Society, 2016) asegura que el saldo de muertes desde que empezó la narcoguerra (2006-2015) es de 150,000, aunque no aclara cuántas de esas bajas son hombres y cuántas mujeres. Lo que sí deja claro es que "La evidencia sugiere que este incremento se debió a la violencia perpetrada por el crimen organizado y a la estrategia de seguridad del Estado, que recurría excesivamente al uso indiscriminado y extrajudicial de la fuerza”. La información sobre las víctimas según su género es marginal. Sobre las mujeres se limita a decir que "una fuente" dice que entre 2006 y 2012 se produjeron 4,306 feminicidios en México. También que, “en algunos lugares”, las mujeres han sido blanco específico de “algunos asesinatos”, como en Ciudad Juárez.

Como este informe, los de otras importantes organizaciones de derechos humanos nacionales e internacionales — desde Amnistía Internacional y el Centro de Derechos Humanos Miguel Agustín Pro Juárez, hasta el Ciudadano en Apoyo a los Derechos Humanos (CADHAC) y la Comisión Mexicana de Defensa y Promoción de Derechos Humanos (CMDPDH) - no vinculan la violencia contra las mujeres con la dinámica de violencia criminal. El caso de Ciudad Juárez es mencionado casi siempre cuando llegan a hablar de la violencia contra las mujeres. Al Estado de México, que es el nuevo Juárez, lo analiza la CMDPDH, pero este caso es la excepción y no la regla. La estadística que sustenta la existencia de la crisis de derechos humanos pareciera indicar que la violencia se ensaña sádicamente con hombres y deja a las mujeres la organización del duelo colectivo. Pero si se cruza la estadística de victimización, criminalidad e impunidad, se podrá constatar que la violencia contra las mujeres también es alta y está en aumento.

Mi hipótesis es que la violencia contra las mujeres queda invisibilizada en la estadística de violaciones a los derechos humanos porque la violencia criminal se atribuye a una sola guerra con dinámica político-estatal, cuando en realidad estamos hablando de dos, no 
necesariamente con fines de control político. La interpretación analítica que se propone es que se trata de dos guerras necropolíticas, la guerra por la gubernamentalización necropolítica del Estado y la guerra por la desposesión de cuerpos femeninos. De estas dos guerras sólo escuchamos sobre la primera, conocida como la narcoguerra, donde la mayoría de las víctimas directas son hombres. La segunda afecta a las mujeres en lo individual y no sólo como familiares, pero no escuchamos de ella ya sea porque las cifras no tienen consideraciones de género o porque se piensa que es algo encapsulado en Ciudad Juárez.

Para desarrollar este argumento, primero caracterizaré la violencia contra las mujeres analizando críticamente la estadística de asilo, desplazamiento, feminicidio, victimización, violencia sexual y desaparición forzada. Con esta base empírica, definiré la necropolítica según Sayak Valencia (2010) y caracterizaré las guerras necropolíticas, su tipología y sus características.

\section{La invisibilización de la violencia contra las mujeres en la crisis de derechos humanos}

Los informes de derechos humanos dan la impresión de que la crisis de derechos humanos afecta mayoritariamente a hombres. Si se toma en cuenta la estadística de asilo y desplazamiento forzado como indicador de que la crisis de derechos humanos está expulsando gente, las cifras producidas en México y por la Agencia de las Naciones Unidas para los Refugiados (ACNUR), simplemente confirman esta creencia. Sin embargo, la interpretación de los datos cualitativos del asilo y del desplazamiento, así como los informes de feminicidio, victimización, violencia sexual y desaparición forzada indican que estos informes no muestran el panorama completo de la crisis sino, por el contrario, invisibilizan la violencia que sufren las mujeres, como se examina a continuación.

Según los informes anuales de la ACNUR, de 2006 a 2015, un total de 98,547 mexicanos huyeron del país. El análisis general de la agencia es que el principal motivo del éxodo es la 
narcoviolencia, pero sus cifras no tienen un registro de género y sólo proporcionan la cifra global por país. No se sabe cuántos de estos casi 100,000 nacionales de México son hombres y cuántos son mujeres (UNHCR, 2007; 2008; 2009; 2010; 2011; 2012; 2013; 2014; 2015).

No obstante, la ACNUR ha hecho un estudio sobre mujeres centroamericanas y mexicanas que han huido de sus países y solicitado asilo en Estados Unidos. Las entrevistas cualitativas realizadas a 160 mujeres en 2015 (37 mexicanas en edades de 18 a 57 años) indican que la violencia de las maras y los cárteles las afecta en la medida en que ellas no pueden hacer sus labores cotidianas, y se resisten a unirse a las bandas criminales como objetos sexuales. Dice que la violencia criminal las afecta “directamente” porque sus hijos, parejas u otros familiares son amenazados, secuestrados, extorsionados o asesinados, no porque sus cuerpos son directamente violentados. Aun así, constata que las mujeres sufren violencia física y sexual en el hogar que las autoridades no atienden; en muchas ocasiones, los perpetradores son parte de estas autoridades (UNCHR, 2015).

También las cifras de desplazamiento forzado nacionales invisibilizan las particularidades de género, pues aseguran que la causa principal es la violencia generalizada por actividades criminales (CMDPDH, 2014; CNDH, 2016; Rubio Díaz-Leal, 2014). Como antecedente de este desplazamiento, los estudios citan el generado por conflictos étnicos y religiosos en Chiapas y Oaxaca, y el producido por violencia sexual en Ciudad Juárez (Rubio Díaz-Leal, 2014). Si nos atenemos a los informes, la violencia sexual sólo provocó desplazamiento en los noventa. Por su parte, el informe de desplazamiento interno, internacional, más importante, el del Internal Displacement Monitoring Centre (IDMC), señala que de 2006 a 2014, por lo menos 481,000 personas fueron desplazadas internamente en México. Tan sólo en 2014, 9,000 personas fueron desplazadas en 23 eventos masivos en Estado de México, Sinaloa, Tamaulipas, Chihuahua, Veracruz, Michoacán, Chiapas, Oaxaca, Coahuila y Ciudad de México. No se indica cuántas mujeres formaban parte de estos colectivos desplazados, pero se asegura que el desplazamiento es por violencia criminal (IDMC, 2015, pp. 9-21). 
En contraste con la información producida en México, las cifras del IDMC — sin ser muy específicas por país - registran el desplazamiento por violencia sexual de manera regional, y señalan que además de la violencia criminal, las mujeres de Centroamérica y México enfrentan violencia sexual e intrafamiliar. Según el IMDC, 21,500 personas jóvenes de Guatemala, El Salvador, Honduras y México han tenido que dejar sus países en búsqueda de protección internacional o simplemente para huir de violencia sexual sistemática y generalizada; 18,800 de ellas son mujeres (87.44\%). De estas mujeres, 23\% son jóvenes menores de edad, de entre 12 y 17 años (IDMC, 2015). Si nos atenemos a estas cifras, casi el 90\% de las personas que huyen por esta violencia son mujeres jóvenes.

Los indicios de una violencia de género vinculada a la narcoguerra que aparecen en el informe del IDMC se amplían al hacer un análisis cualitativo de los casos de persecución de mujeres asiladas o con solicitud de asilo. No obstante, en los casos de mujeres asiladas o en proceso de asilo en Estados Unidos y Canadá ${ }^{1}$ son pocos los registros de mujeres víctimas de persecución por negarse a pagar extorsión, ser testigo de un crimen o informante del narco, empresaria o propietaria de ranchos. Los casos de mujeres directamente vinculados a la narcoguerra están relacionados con el reclamo de justicia o con su labor en cuanto activistas contra el feminicidio. En este contexto, las mujeres llegan acompañando a sus parejas perseguidas, y este parentesco es lo que las hace víctimas de persecución junto con sus hijos, hijas, cuñadas, madres, suegras, etcétera, porque muchos huyen en familias de hasta 20 o 30 miembros.

Las bases de datos más especializadas en género indican que las mujeres mexicanas, igual que las guatemaltecas, hondureñas y salvadoreñas, huyen por persecución feminicida constituida de violencia intrafamiliar y sexual en el hogar y en el espacio público, a veces

\footnotetext{
${ }^{1}$ En los casos disponibles en el Centro de Estudios de Género y Refugiados (Center for Gender \& Refugee Studies, San Francisco, California), se incluyó también la persecución y la violencia sexual contra dos hombres homosexuales. El periodo cubierto es 1998-2014. Asimismo, se consultaron los archivos legales del bufete de abogados de Carlos Spector, en El Paso, Texas, que incluían casos del periodo 2006-2012. Otros casos consultados verbalmente fueron los del Instituto de Asilo y Migración del Sudeste (Southwest Asylum \& Migration Institute, Nuevo México). En Canadá se consultó la base de datos de casos del Immigration and Refugee Board of Canada.
} 
perpetrada por alguna pareja o familiar relacionados con la delincuencia organizada. La mayor parte de las solicitudes de asilo de mujeres tienen que ver con el abuso de la pareja, incluyendo violencia sexual, violencia sexual no doméstica, normas sociales represivas, abuso infantil e incesto. Los perpetradores son fundamentalmente parejas y padres que, en algunos casos, son agentes estatales que trabajan para los cárteles o que son protegidos por el pacto patriarcal de las instituciones públicas. En todos los casos, las mujeres reclamaron justicia, pero las autoridades no la proporcionaron por la impunidad y la misoginia institucional.

Esta información cualitativa tiene un correlato en las cifras nacionales sobre victimización y violencia sexual e intrafamiliar, desaparición forzada y feminicidio, mismas que los informes de derechos humanos no analizan y las estadísticas de asilo ni siquiera consideran.

En primer lugar, sobre victimización (víctimas del delito) y violencia sexual (ataques e insinuaciones sexuales sin consentimiento e impuestas por medios violentos), las cifras indican que las mujeres son las principales víctimas de delitos relacionados con la esclavitud sexual y de violencia sexual en los ámbitos público y privado. La Comisión Interamericana de Derechos Humanos (CIDH) dice que en 2012 más mujeres que hombres fueron víctimas de delitos graves tales como violación (82\%); trata (82\%); tráfico (81\%); abuso sexual (79\%); violencia intrafamiliar (79\%); violación (71\%); delitos contra la familia (56\%); y delitos contra la libertad (83\%). El índice de victimización indica que esta tendencia se ha incrementado, dado que en 2010 el 43\% de las víctimas del delito eran mujeres, para 2014 el porcentaje ascendió a 51\%, mientras que el de hombres disminuyó de 53\% a 48\%, respectivamente (CIDH 2015, p. 75, pp. 93-100, p. 117, p. 121).

Con información de las autoridades judiciales sobre delitos sexuales, la Comisión Ejecutiva de Atención a Víctimas (CEAV) confirma lo referente a la violencia sexual: 81\% de las víctimas de delitos sexuales entre 2010 y 2015 fueron mujeres. En 60\% de los casos de violencia sexual los agresores eran conocidos de las víctimas; en $24 \%$ de los casos eran sus parejas. En $40 \%$ de los casos las agresiones se dieron en escuelas, en 31\% en instituciones públicas y en 5.3\% en el hogar. Los servicios de salud dijeron que de los casos atendidos, 
97\% de los agresores eran hombres, y 94\% de las víctimas fueron mujeres, quienes en $60 \%$ de los casos dijeron ser objeto de violencia subsecuente y en 70\% tenían entre 16 y 45 años (CEAV, 2016).

Asimismo, las cifras más recientes de violencia en el hogar del INEGI (2011) indican que 44.8\% de 24,566,381 mujeres casadas o en unión libre en México habían sufrido violencia en el hogar, $25.8 \%$ de ellas había sido objeto de violencia física; $11.7 \%$, de violencia sexual; 56.4\% de violencia económica; y 89.2\% de violencia emocional. La violencia contra la mujer es más frecuente en Baja California, Sonora, Aguascalientes y Querétaro, así como en algunos de los estados con problemas de narcotráfico y con los índices de feminicidio más altos, como veremos adelante: Ciudad de México, Estado de México, Jalisco, Chihuahua y Nuevo León (INEGI, 2013, p. 9, p. 12, p. 56, p. 60).

En segundo lugar, sobre desaparición forzada, las cifras de 2006 a 2014 contabilizaban 23,271 personas desaparecidas, $70 \%$ de las cuales eran varones y 30\% menores de 18 años. Si bien la mayoría son hombres, hay tres datos que ligan a la desaparición forzada con la violencia sexual e intrafamiliar que está expulsando a las mujeres del país:

a) Como con respecto a la victimización, los casos de mujeres como blanco de la desaparición forzada están al alza: según datos analizados por la revista Nexos, en 2011 había 1,930 más hombres desaparecidos que mujeres, pero en 2014 —año en que la desaparición forzada de mujeres tuvo su pico más alto- la diferencia cayó a 1,095. Esto indica que mientras que la tasa de hombres desaparecidos disminuyó en casi $1 \%$, la de mujeres creció 49\% (Merino, Zarkin y Fierro, 2015).

b) Entre 2011 y 2015, 7,185 mujeres habían sido reportadas como desaparecidas, la mitad de ellas menores de 18 años, cifra que coincide preocupantemente con la edad de mujeres desplazadas por violencia y trata sexual, y que indica que un porcentaje importante del $30 \%$ de personas menores de edad desaparecidas eran mujeres. De hecho, según la ONU, el número de niñas (menores de 18 años) es 1.8 veces mayor que el de niños (Proceso, 2016). 
c) Los municipios con mayor número de mujeres desaparecidas recientemente están en: 1) estados donde hay mayor número de feminicidios, como Estado de México, Guerrero, Jalisco, Nuevo León y Oaxaca; 2) estados donde se han ubicado desplazamientos forzados masivos como Tamaulipas y Coahuila; y 3) estados donde la violencia intrafamiliar es más alta, como Sonora (Merino, Zarkin y Fierro, 2015).

En tercer lugar, respecto del feminicidio, desde 1993 más de 40,000 mujeres han sido asesinadas por ser mujeres. Los estados con mayor índice de feminicidios concurren con aquellos donde las tasas de violencia sexual e intrafamiliar y de desaparición forzada de mujeres son también más altas: Chiapas, Chihuahua, Ciudad de México, Guerrero, Jalisco, Estado de México, Nuevo León, Oaxaca, Puebla y Sinaloa (CIDH, 2015). Seis de estos estados están en la lista con más desplazamientos forzados masivos —Estado de México, Sinaloa, Chihuahua, Chiapas, Oaxaca, Ciudad de México. Si bien, las cifras globales de homicidio indican que los hombres tienen mayor probabilidad de ser asesinados, desde 2010 hay una tendencia al alza en el caso de mujeres asesinadas de entre 20 y 30 años, lo que coincide con el incremento de feminicidios y violencia intrafamiliar en el hogar contra mujeres en ese rango de edad (INEGI, 2015).

En la inconsistencia para mostrar el miedo de persecución específico de las mujeres y en la consistencia en los altos índices de violencia sexual e intrafamiliar en los ámbitos público y privado, las cifras expuestas indican que las mujeres sufren de violencia sexual e intrafamiliar que, si bien no responde a las dinámicas de peleas entre cárteles, sí tienen que ver con hombres vinculados a ellos, y con su misoginia y actividades en la economía criminal, no necesariamente del trasiego de drogas sino de esclavitud sexual con fines comerciales. Se trata de una violencia que es el contínuum de la narcoguerra; esa violencia se presenta aquí como una guerra adyacente a la narcoguerra, y ambas son acepciones de lo que llamo las guerras necropolíticas.

\section{Los cuerpos de las mujeres y las guerras necropolíticas}


Aun cuando el término de necropolítica se atribuye al africano Achille Mbembe, ${ }^{2}$ la definición que interesa aquí es la de la feminista tijuanense Sayak Valencia, quien la mexicaniza y dice que en las sociedades hiperconsumistas los cuerpos se convierten en una mercancía, y su cuidado, conservación, libertad e integridad son productos relacionados (Valencia, 2010). Para ella, los cárteles ejercen un poder de opresión análogo al del Estado y se han convertido en un Estado paralelo que reconfigura la biopolítica y utiliza técnicas que denomina necroprácticas —acciones radicales dirigidas a infringir dolor, sufrimiento y muerte. Al igual que el Estado legítimo, su contraparte criminal pretende tener el control sobre el territorio, la seguridad y la población, es decir, de gobernar a través de la explotación de los recursos nacionales y las personas, y la venta de seguridad privada. Controlan los cuerpos de hombres y mujeres, haciéndolos mercancías de intercambio o consumidores de los bienes ofertados en el narcomercado (Valencia, 2010).

Esta interpretación de la necropolítica complementa la discusión sobre nuevas guerras de Mary Kaldor (2006), quien no nombra textualmente la violencia criminal pero la describe. Kaldor asegura que las nuevas guerras no constituyen simples guerras civiles o conflictos de baja intensidad, conceptos ampliamente utilizados durante la Guerra Fría. Tampoco son guerras informales o privatizadas. Más bien, dice, son “posmodernas”, en el sentido de que

2 Mbembe sostiene que la biopolítica no es suficiente para entender cómo la vida se subordina al poder de la muerte en África. Afirma que la proliferación de armas y la existencia de mundos de la muerte - lugares donde la gente se encuentra tan marginada que en realidad viven como muertos vivientes - son un indicador de que existe una política de la muerte (necropolítica) en lugar de una política de la vida (biopolítica) como la entiende Foucault. Examina cómo el derecho soberano de matar se reformula en las sociedades donde el estado de excepción es permanente. Según Mbembe, en un estado sistemático de emergencia el poder se refiere y apela constantemente a la excepción y a una idea ficticia del enemigo. Afirma que las operaciones militares y el derecho de matar no son ya prerrogativas exclusivas del Estado gubernamentalizado, y que el ejército regular no es ya el único medio para ejecutar el derecho de matar. Las milicias urbanas, los ejércitos privados y las policías de seguridad privada tienen también acceso a las técnicas y prácticas de muerte. La proliferación de entidades necroempoderadas, junto con el acceso generalizado a tecnologías sofisticadas de destrucción y las consecuencias de las políticas socioeconómicas neoliberales, hace que los campos de concentración, los guetos y las plantaciones se conviertan en aparatos disciplinarios innecesarios porque son fácilmente sustituidos por la masacre, una tecnología necropolítica que puede ejecutarse en cualquier lugar en cualquier momento (Mbembe, 2011). 
es imposible distinguir lo público de lo privado, así como los motivos económicos de los políticos (Kaldor, 2006). Las nuevas guerras ocurren al interior del Estado en vez de entre Estados, y son resultado del desmantelamiento neoliberal de éstos, pues se dan en situaciones en las que el ingreso del Estado disminuye por un debilitamiento de la economía y la propagación de la criminalidad, la corrupción y la ineficiencia. Según Kaldor (2006) la violencia se privatiza debido al crecimiento del crimen organizado, la emergencia de grupos paramilitares y la pérdida de legitimidad política. El Estado pierde control sobre partes de su territorio a manos de los grupos criminales. Las nuevas guerras ocurren, pues, en la lucha por el necropoder.

Al estar enfocadas en la lucha por el necropoder, estas nuevas guerras de las que habla Kaldor tienen particularidades en el tercer mundo, donde el necropoder gira no sólo en torno a la delincuencia, el paramilitarismo y los mercenarios, sino del control del mercado de cuerpos y otras mercancías ilícitas. Por ello, propongo llamarlas guerras necropolíticas, de las que por lo menos hay dos tipos: 1) las guerras por ganar la alianza con el Estado en la reproducción del capital criminal en general, o guerras por la gubernamentalización necropolítica del Estado; y 2) las guerras contra las mujeres para desposeerlas de sus cuerpos para el dominio misógino privado y la explotación sexual, o guerras por la desposesión de cuerpos femeninos.

\section{Guerra por la gubernamentalización necropolítica del Estado}

Comparto con Valencia (2010) la idea de que el necropoder es una apropiación criminal de los elementos fundamentales de la biopolítica — territorio, seguridad y población-, pero no coincido en que se erige como un Estado paralelo. La evidencia en estudios empíricos sobre la reconfiguración cooptada del Estado (Flores Pérez, 2012; 2013) sugiere que a diferentes niveles de gobierno el necropoder y el Estado son uno solo, es decir, los criminales fungen como el brazo armado del poder estatal para regular la muerte de la población en función de la reproducción del capital delincuencial. Mi hipótesis es que, 
aunque siempre ha habido relación entre criminales y el Estado en México como lo indica Flores Pérez (2012; 2013), la guerra contra el narco permitió la intensificación de los lazos porque condujo a las fuerzas armadas y las diversas policías a la disyuntiva de plata o plomo, haciendo que exista una pelea entre los cárteles por ganar el favor de éstos.

Sobre gubernamentalidad, en el marco foucaultiano, la palabra gobierno no se refiere a la institución de gobierno sino a "una actividad encaminada a conducir a los individuos a lo largo de sus vidas poniéndolos bajo la autoridad de una guía responsable de lo que hacen y lo que pasa con ellos” (Foucault 1997, p. 67). Para Foucault, las técnicas de gobierno no son exclusivas del Estado pues constituyen el conjunto de acciones sobre las acciones posibles de otros sujetos, o las acciones ejercidas sobre sí para dominar placeres o deseos: “Gobierno de niños, gobierno de almas y conciencias, gobierno de una casa, de un estado, o de uno mismo” (Foucault, 1997, p. 81). Para diferenciar la gubernamentalidad política de las de otra índole, Foucault llamó a ésta la gubernamentalización del Estado.

Por ello, aquí se propone hablar de la gubernamentalización necropolítica del Estado, misma que implica la delegación de autoridades estales a bandas criminales, de las técnicas de dominación de la población para actuar sobre sus acciones a través de prácticas que producen muerte (asesinato, tortura, persecución, tráfico de personas, trata sexual). La gubernamentalización necropolítica del Estado usa discursos políticos como la guerra contra el narcotráfico o la crisis de inseguridad como dispositivos de regulación de la muerte; la securitización del espacio público como su estrategia central; y la economía criminal como su principal motivación.

La gubernamentalización necropolítica del Estado dirige la conducta de policías y militares hacia una situación en la que el manejo experto de tecnologías de muerte, se convierte en una ventaja comparativa en un contexto de salarios de miseria y subordinación de lo ético al mercado y al consumo. La guerra necropolítica por la gubernamentalización del Estado implica una guerra entre grupos criminales para ganar la capacidad de servir como el gobierno privado indirecto del Estado, como han expuesto Bunker (2011) y Sullivan (2012). Estos autores dicen que los cárteles mexicanos son el arquetipo de un tipo de 
insurgencia que en los noventa solamente era una teorización: la insurgencia criminal (Bunker, 2011; Sullivan, 2012). La insurgencia criminal es el resultado de la lucha entre bandas criminales por el necropoder. Su competencia con éste no es por la tradicional participación política dentro de las estructuras estatales —como los partidos políticos, digamos - sino para liberarse del control estatal y así poder maximizar sus ganancias ilegales.

En resumen, lo que conocemos como la narcoguerra sería una guerra por la gubernamentalización necropolítica del Estado, es decir, una disputa entre cárteles por el trato preferencial del Estado y su asociación con él. Pero esta guerra mutó. Si bien en un principio era una guerra por poder territorial y control del mercado de la droga, los objetivos económicos se desviaron a mercados y mercancías con igual valor comercial que la droga, pero sin el creciente costo en riesgo y seguridad. Esta mercancía resultó ser el cuerpo de las mujeres. La mercantilización de los cuerpos femeninos, la exacerbación de la misoginia, la impunidad sistémica y los riesgos crecientes en el comercio de drogas han colocado a las mujeres como adversarias en otra guerra necropolítica, una que es paralela a la narcoguerra y que protagonizan los mismos hombres involucrados en ella, pero también muchos de los hombres que han sido o pueden ser objeto de la narcoviolencia. Es una guerra en la que la víctima de la guerra contra el narco también es potencialmente victimario, porque lo que está en juego no es territorio ni poder ni control sobre el mercado de drogas ilícitas, sino la desposesión de los cuerpos de las mujeres para dominarlos y lucrar con ellos sexualmente.

\section{La guerra por la desposesión de cuerpos femeninos}

Kaldor apunta como característica general de las nuevas guerras el uso de la violación y otros crímenes de orden sexual como parte de su estrategia de dominación. La antropóloga Rita Laura Segato (Segato, 2006; 2014) coincide con Kaldor, pero ahonda en el uso de la tortura y la esclavitud sexual que fueron paradigmáticas de las nuevas guerras 
ejemplificadas en Ruanda y la ex Yugoslavia, y dice que en este paradigma "la agresión, la dominación y la rapiña sexual ya no son, como fueron anteriormente, complementos de la guerra, daños colaterales, sino que han adquirido centralidad en la estrategia bélica” (Segato, 2014, p. 343). Para ella, la violencia “corporativa y anómica se expresa de forma privilegiada en el cuerpo de las mujeres”, pues los agentes violentos “escriben” en sus cuerpos para hacerlos el "bastidor en el que la estructura de la guerra se manifiesta" (Segato, 2014, p. 344).

Las definiciones de Kaldor (2006) y Segato (2014) son un comienzo para colocar el papel central del cuerpo de las mujeres en acciones de guerra, pero los siguen supeditando a una estrategia bélica que tiene como fin la dominación de un territorio para fines independientes a los del uso de los cuerpos femeninos. En cambio, lo que se sugiere aquí es que éstos tienen un rol central como mercancía y como fin en sí mismos. Mientras que la gubernamentalización necropolítica del Estado puede constituir una nueva guerra en la que los sujetos que se disputan el necropoder son criminales que luchan por la preferencia del Estado, la violencia contra las mujeres constituye una disputa por el control de mercancías ilícitas, sólo que en este caso el enemigo y la mercancía son la misma cosa, son las mujeres y sus cuerpos cosificados y objetivados sexualmente. A las mujeres hay que disputarles el control de sus cuerpos mediante violencia física y sexual extrema, porque sólo así pueden ser desposeídas de ellos para mercantilizarlos en el mercado sexual. Es un insumo vivo que hay que desposeer mediante tortura y muerte.

Para poder analizar el rol de los cuerpos femeninos como mercancías en guerras necropolíticas, propongo introducir la idea de desposesión de Judith Butler (Butler y Athanasiou, 2013). Butler dice que la desposesión tiene dos acepciones: 1) el sujeto desposeído en cuanto que descentrado de sí mismo, lo cual le permite conectarse de forma relacional con otros y la sociedad; y 2) el despojo de medios de subsistencia o “acumulación por desposesión” (Harvey, 2004), que radicaliza la acumulación “originaria” de Karl Marx, refiriéndose a “la depredación, el fraude y la violencia” que conlleva esta actividad que extrae los recursos de la naturaleza y la tierra para privatizarlos y lucrar con ellos. 
Para Butler, la desposesión en la primera acepción es determinante en la segunda, pues incluso cuando gozamos de derechos somos dependientes de un tipo de gobernanza y un régimen legal que nos confiere esos derechos y delimita nuestro actuar, de tal forma que antes de que exista una posibilidad de ser desposeído ya estamos fuera de nosotros mismos. Somos sujetos interdependientes cuyo placer y sufrimiento depende desde el principio de un ambiente sostenible, por ello cuando alguien nace en condiciones de precariedad extrema, su vida se encuentra ya en desposesión. En otras palabras, “solamente podemos ser desposeídos porque ya estamos desposeídos” (Butler y Athanasiou, 2013, p. 5).

Esta idea constitutiva de desposesión subjetiva y objetiva permite entender cómo un entorno social misógino y de impunidad estructural de la violencia sexual e intrafamiliar, es la condición de posibilidad para que sujetos violentos y misóginos escindan a las mujeres de sus cuerpos para ser esclavizadas, forzadas mediante violencia física, engaños y depredación a ser mercancías sexuales.

Pero, ¿en qué momento se puede asegurar que esta desposesión de cuerpos constituye una guerra? La guerra por la desposesión de cuerpos está directamente relacionada con las actividades violentas y la autoafirmación de los sujetos centrales de la narcoguerra: utiliza las mismas técnicas de extracción, es decir, el asesinato y la desaparición forzada. Sin embargo, la guerra necropolítica por desposesión no es entre bandas criminales que se disputan el control del mercado de drogas y la asociación con el Estado, sino entre hombres violentos y precarizados, y mujeres que se resisten a ser desposeídas de sus cuerpos. La guerra por los cuerpos femeninos tiene su primera línea de batalla donde están las mujeres más pobres y marginadas de las zonas rurales y conurbadas de las grandes ciudades.

Esos cuerpos son extraídos de sus dueñas a través de brutalidad física y sexual para ser esclavizadas y despojadas de su voluntad con amenazas contra ellas o sus hijos, la tortura y la migración forzada. Luego de ser extraídos, los cuerpos son usados en esclavitud con fines de comercio sexual o para controlarlos con fines de subordinación doméstica y sexual. La guerra por desposesión de cuerpos femeninos es una guerra cuya existencia se refleja en 
los datos, pero ha sido invisibilizada en la impunidad estructural y selectiva que desprecia a las mujeres y minimiza su experiencia de sufrimiento a la completa inexistencia.

\section{Características de las guerras necropolíticas}

La trata y el feminicidio existían desde antes de que la política antidrogas fuera nombrada "guerra contra el narco". No es decir que los hechos que se explican hayan empezado con la narcoguerra, sino que las guerras necropolíticas pueden ser un marco que interpreta y nombra sucesos que empezaron hace muchos años y que tienen características compartidas que se han enfatizado y entrecruzado de tal forma en años recientes que pueden nombrarse así. No es que se proponga analizarlas por separado, sino que hacen referencia a un tipo de guerra (necropolítica) con diferentes objetivos, de allí que se proponga una tipología. Las guerras necropolíticas son tales porque comparten al menos tres características: 1) la ley opera para mantener la impunidad y las condiciones en las que las violaciones a los derechos humanos se invisibilizan, sobre todo en el caso de las mujeres; 2) la subjetividad endriaga (Valencia, 2010) es la protagonista de la violencia; y 3) el uso de desaparición forzada, masacre y feminicidio constituyen técnicas de acumulación de capital (droga en el caso de la guerra criminal y cuerpos femeninos en la guerra por desposesión).

\section{Invisibilización de violaciones a los derechos humanos}

Las violaciones a los derechos humanos en las guerras necropolíticas ocurren en un campo nebuloso entre lo privado y lo público; y en la guerra por la desposesión de cuerpos femeninos, la impunidad estructural que afecta todo el sistema judicial oscurece la magnitud de las mismas. Sin embargo, las violaciones a los derechos humanos resultan invisibilizadas por dos razones: 1) el colapso espacial de la dicotomía público/privado para 
fines de identificar la atribución estatal en la responsabilidad de derechos humanos; y 2) la impunidad estructural.

\section{Colapso de lo público y lo privado}

Las violaciones a los derechos humanos como concepto jurídico son producto de un proceso de interpretación legal en el que ciertos hechos se construyen como violaciones a los derechos y otros no. El punto clave es que los atentados ocurran en el ámbito de lo público, es decir, la arena político-estatal. Las actividades criminales no son consideradas públicas en la medida en que el discurso legal hace creer que no ocurren en el ámbito político-estatal.

Las juristas feministas Chinkin (1999) y Gal (2005) aseguran que la dicotomía público/privado en la ley siempre ha sido artificial, construida a través del lenguaje, y sirve a propósitos ideológicos (Gal, 2005, p. 25). Chinkin cree que esta división tiene importantes consecuencias para la legislación internacional, especialmente la de derechos humanos, porque define una visión estado-céntrica de la responsabilidad y la atribución. Asegura que la demanda de aplicación universal de los derechos humanos asume una racional poco cuestionada de distinguir entre la conducta de los órganos estatales y los de otras entidades cuya definición en realidad depende de las convicciones filosóficas referentes al adecuado rol del gobierno y de la intervención gubernamental (Chinkin, 1999).

Según la división público/privado que permea el discurso de derechos humanos, las actividades criminales se dan en el ámbito de la economía criminal y no constituyen un problema de carácter público, entendido éste como el ámbito de la política del Estado. En México el escenario de lo público/privado ya no es claro, y eso sirve para ocultar las dinámicas de poder detrás de las violaciones a los derechos humanos, como lo indica el Informe Bourbaki, el cual dice que en la narcoguerra las “bajas humanas” se producen en 
“dominios de orden delictual” (criminales) y en “dominios de orden legal” (agentes de alguno de los poderes del Estado), pero de forma híbrida (Equipo Bourbaki, 2011, p. 9).

Este entrelazamiento de lo estatal con lo criminal es lo que los estudiosos de las mafias denominan intreccio, que significa "más que reciprocidad entre la mafia y el Estado; apunta hacia una vasta área gris en la que es imposible determinar dónde termina una y empieza la otra” (Schneider y Schneider 2003, pp. 33-34). No obstante, el entrelazamiento denso de las mafias con el Estado no es unitario (Schneider y Schneider, 2003, p. 31), por lo que implica generalmente un alto nivel de inconsistencia interna (Schneider y Schneider 2003, pp. 3334). Esto es lo que Auyero ha denominado el "área gris del poder”, que implica la fusión de las actividades violentas de quienes las perpetran y de quienes deberían prevenirlas (Auyero, 2007, p. 32). Para Auyero, la zona gris es al mismo tiempo un objeto empírico y una lente analítica que dirige la atención hacia un área turbia en la que las fronteras normativas se disuelven, en la que los actores estatales y las élites políticas promueven o toleran y/o participan en causar daño (Auyero, 2007, p. 32). Las violaciones a los derechos humanos ocurren en el área gris y no se registran.

\section{Impunidad}

En México la impunidad no es simple resultado de la impericia o la incapacidad para investigar, sino de la reconfiguración cooptada del Estado, la cual se da a partir de lo que se ha denominado “captura” del Estado, que es un tipo de corrupción institucional en la que empresarios y agentes del Estado establecen alianzas para beneficio propio, ignorando las reglas de competencia, y con el objetivo explícito de establecer reglas económicas que buscan beneficiarlos a ellos y no el interés público (Flores Pérez, 2013). De esta forma, la corrupción traspasa el simple soborno y se vuelve institucionalizada. Cuando en vez de empresarios son criminales, y en vez de captura de instituciones y reglas económicas se capturan instituciones de procuración de justicia y del orden público, estamos hablando de un proceso de reconfiguración cooptada del Estado, porque lo que se coopta son las 
instituciones "encargadas de reforzar las disposiciones normativas más esenciales del Estado” (Flores Pérez, 2013, p. 50).

La impunidad como resultado de la reconfiguración cooptada del Estado es parte importante de la gubernamentalización necropolítica del Estado. De acuerdo con las propias autoridades mexicanas (citadas en Sullivan, 2012), más de la mitad de los municipios del país (60-65\%) han sido impactados por la delincuencia organizada. Los cárteles de la droga han infiltrado y usado como base de operaciones de secuestro, extorsiones y robo de vehículos más de 1,500 ciudades. Por ello se ha reconocido la existencia de 980 "zonas de impunidad” en las que las bandas delincuenciales operan sin ningún tipo de restricción. En estas zonas de impunidad hay “enclaves” en los que los grupos criminales ejercen más control territorial que el propio Estado. Estos enclaves se encuentran ubicados en los municipios de las regiones conocidas como Tierra Caliente (Michoacán, Guerrero, Colima y Estado de México), Triángulo Dorado (Chihuahua, Durango y Sinaloa), el Istmo de Tehuantepec (Oaxaca), el Valle de Juárez (Chihuahua), Tamaulipas, y la zona metropolitana de la Ciudad de México (Sullivan, 2012, p. 17, p. 20). Según el Índice Global de Impunidad México 2016, que analiza datos de 2010 a 2012, sólo 4.46\% de los delitos consumados reciben sentencias condenatorias, lo que implica un índice de impunidad de 95\%. La cifra negra de delitos no denunciados haría que esta cifra se elevara a 99\% (Le Clercq Ortega y Sánchez Lara, 2016).

La impunidad también es fundamental para asegurar la desposesión de cuerpos. Aun cuando el índice global no reporta específicamente la impunidad en delitos por género, se puede apreciar que aquellos lugares donde hay violencia sexual e intrafamiliar, desaparición forzada de mujeres y feminicidio, se ubican en Estados con márgenes que van de impunidad media (56-60\%), como la Ciudad de México, Chihuahua, Sonora y Chiapas; impunidad alta (65-70\%), como Jalisco, Puebla, Sinaloa, Tlaxcala; y muy alta (70-76\%), como Estado de México, Nuevo León, Oaxaca, Tamaulipas, Coahuila y Guerrero (Le Clercq Ortega y Sánchez Lara, 2016). 
Además, la violencia intrafamiliar es el delito más frecuente en Chihuahua y San Luis Potosí, donde el nivel de impunidad es media, lo cual significa que no se investigan más de la mitad de los casos. Este delito también está entre los cinco más habituales en Baja California Sur, Nuevo León, Puebla y Quintana Roo. No obstante que Chihuahua es un estado catalogado de impunidad media, es donde se tienen los índices de desplazamiento, violencia sexual e intrafamiliar y feminicidio más altos. Baja California Sur, Nuevo León y Quintana Roo cuenta con niveles de impunidad muy altos, y en uno de ellos, Nuevo León, la violencia intrafamiliar y sexual, la desaparición forzada y el feminicidio, tienen uno de los índices más altos del país. De hecho, en Nuevo León, Puebla y Baja California es donde hay más averiguaciones previas por delitos sexuales (2010-2015) (Le Clercq Ortega y Sánchez Lara, 2016; CEAV, 2016). Puebla tiene impunidad de rango alto, y está en la lista de estados con mayor número de feminicidios. También entre los estados con mayor recurrencia en el delito de incumplimiento de asistencia familiar se encuentran Chiapas, con altos índices de feminicidio; y Sonora, con alta tasa de desaparición forzada.

El índice de impunidad no desagrega su información por género, pero los delitos de lesiones y homicidio pueden incluir violencia sexual e intrafamiliar y desaparición forzada, feminicidio y desplazamiento forzado, y eso nos permite cruzar la información de impunidad con la de las violaciones a los derechos humanos de las mujeres. Por un lado, el delito de lesiones está entre los cinco más frecuentes en casi todo el país, incluyendo los 10 estados con mayor índice de feminicidio, los ocho con mayor concentración de desaparición forzada de mujeres, los nueve con más violencia intrafamiliar y los 10 con mayor número de desplazamientos forzados masivos: Aguascalientes, Baja California, Baja California Sur, Chiapas, Chihuahua, Coahuila, Ciudad de México, Guerrero, Guanajuato, Hidalgo, Jalisco, Estados de México, Michoacán, Morelos, Nayarit, Nuevo león, Oaxaca, Puebla, Querétaro, Quintana Roo, San Luis Potosí, Sinaloa, Sonora, Tabasco, Tamaulipas, Tlaxcala, Veracruz, Yucatán y Zacatecas. Por otro lado, el delito de homicidio está entre los cinco más recurrentes en Chiapas, Guerrero y Sinaloa, donde la impunidad es de media a muy alta y donde el feminicidio es más común (Le Clercq Ortega y Sánchez Lara, 2016). 


\section{El endriago}

La subjetividad fundamental de las guerras necropolíticas es lo que Valencia (2010) llama el Sujeto endriago. El endriago es un personaje mítico de la literatura medieval española (Amadís de Gaula). Es un monstruo, un híbrido de hombre, hidra, y dragón; es una bestia de gran altura, fuerte y ágil, que habita tierras infernales y produce un gran temor entre sus enemigos. Valencia adopta el término endriago para conceptualizar a los hombres que utilizan la violencia como medio de supervivencia, mecanismo de auto-afirmación, y herramienta de trabajo. Los endriagos no sólo matan y torturan por dinero, sino que también buscan dignidad y autoafirmación.

Para Valencia, el endriago es la subjetividad disidente del neoliberalismo, pero no significa que sea una resistencia legítima: los endriagos siguen siendo hombres de negocios que toman el neoliberalismo hasta sus últimas consecuencias, resistiendo el Estado neoliberal pero de una manera distópica. Las relaciones de necropoder actúan para inducir a los endriagos a necroprácticas que se ofrecen en el biomercado, las opciones "laborales” que quedan para quienes no pueden afirmarse identitariamente en la economía “legal”. La subjetividad del endriago es en parte posible gracias al patriarcado y los patrones de conducta del tipo de masculinidad hegemónica y violenta. Valencia dice que estos varones no quieren perder su rol de proveedores y dominadores de mujeres y están dispuestos a alquilar sus cuerpos a la prestación de servicios de muerte.

Aunque Valencia no se refiere explícitamente a las fuerzas del orden o a los militares cuando describe al endriago, los datos arrojan que son su mejor expresión, no sólo por su monstruosidad sino también porque en la gubernamentalización necropolítica del Estado mexicano no sólo es híbrido en su naturaleza racional-violenta, sino en su composición criminal-legal, la cual subvierte la división dicotómica de lo público y lo privado a nivel ontológico. 


\section{Desaparición forzada, masacre y feminicidio como tecnologías de muerte}

Como se explicó ya en la definición de las guerras necropolíticas y en sus dos primeras características, el campo de batalla, por así decirlo, es uno semilegal, uno caracterizado por el colapso de lo público y lo privado en el ejercicio de la violencia y en la atribución de los agentes violadores de derechos humanos. De esta forma no podemos esperar que se hable de campos o frentes de batalla como tales. En vez de eso, las tecnologías de muerte que caracterizan a las guerras necropolíticas son tres: la desaparición forzada, la masacre y el feminicidio.

\section{Desaparición forzada}

En la guerra por la gubernamentalización necropolítica del Estado las víctimas son lo mismo militares y policías que indígenas, activistas, comerciantes, migrantes y jóvenes sin ninguna actividad política. En otras palabras, pareciera que cualquiera puede ser víctima de desaparición, aunque debido a la zona gris del poder, no queda claro que estas desapariciones sean desapariciones forzadas en el sentido legal del término.

La desaparición forzada de personas se encuentra sancionada en la Convención Internacional para la protección de todas las personas contra las desapariciones forzadas y en la Convención Interamericana sobre Desaparición Forzada de Personas, que establece que “se entenderá por ‘desaparición forzada’ el arresto, la detención, el secuestro o cualquier otra forma de privación de libertad que sean obra de agentes del Estado o por personas o grupos de personas que actúan con la autorización, el apoyo o la aquiescencia del Estado, seguida de la negativa a reconocer dicha privación de libertad o del ocultamiento de la suerte o el paradero de la persona desaparecida, sustrayéndola a la protección de la ley” (Artículo 2). 
La desaparición forzada es un delito que viola los derechos humanos cuando se ha cometido por un agente del estado o con aquiescencia de éste; es un delito continuado, porque empieza con una detención extrajudicial la cual se niega a familiares, y no prescribe hasta que la persona es encontrada con o sin vida. En el discurso de derechos humanos, como en el caso de persecución y tortura, una desaparición no es forzada si ocurre en el ámbito doméstico o el espacio público a manos de agentes privados.

Lo que ocurre hoy en México desafía esta definición porque las autoridades del Estado no siempre se encuentran inmiscuidas directamente, o por lo menos no de manera obvia o activa. En muchos casos no se sabe el nivel de involucramiento de las autoridades, o no se puede establecer con claridad, pues puede ser a través de una red de corrupción. Es esta incertidumbre que se crea en la zona gris y la impunidad, lo que hace de la desaparición forzada una herramienta útil en la gubernamentalización necropolítica del Estado, pues éste puede deslindarse fácilmente de su responsabilidad al tiempo que parece violencia criminal indiscriminada que lo exculpa de violaciones graves de derechos humanos. Es una estrategia del necropoder para crear zozobra y no rendir cuentas sobre las muertes de hombres y mujeres. La desaparición que sigue al secuestro o detención ilegal por parte de criminales y autoridades contra migrantes, activistas, políticos incómodos, periodistas o víctimas del delito es una forma de diluir responsabilidad.

Respecto de las mujeres, como sabemos por las cifras de muerte y el lugar preponderante de las mujeres en los comités de búsqueda de desaparecidos, en la guerra por el control del mercado de drogas el índice de muerte y desaparición es mayor en hombres. Los efectos en las mujeres son mayoritariamente indirectos (madres, hermanas, esposas, cuñadas, nueras e hijas). Pero esto no implica que las mujeres no sean asesinadas y desaparecidas. Lo son, sólo que la violencia de la guerra por la desposesión de cuerpos femeninos tiene otra dinámica espacio-temporal conformada por la esfera pública no securitizada, el espacio privado o personal, y una combinación de ambas, con fines de dominación y explotación sexual. 
Además, en términos legales, si una mujer es violada, asesinada y desaparecida a través de desintegración química, hundimiento en aguas profundas o entierro clandestino, no constituye desaparición forzada. Es simplemente una desaparición "por voluntad de un particular”. La excepción de esta configuración del delito de desaparición forzada se da en el Estatuto de Roma de la Corte Penal Internacional (CPI), el cual reconoce como desaparición forzada la desaparición de una persona en el contexto de delitos de lesa humanidad, que incluyen "violación, esclavitud sexual, prostitución forzada, embarazo forzado, esterilización forzada u otros abusos sexuales de gravedad comparable” cuando "se cometen como parte de un ataque generalizado o sistemático en contra de una población civil y con conocimiento de dicho ataque” (CPI, 1998Art. 7(1)(g)).

Por ello, la desaparición es la tecnología ideal para someter a las mujeres a la esclavitud sexual comercial, pues, dado que esta práctica es recurrente en el contexto de la narcoviolencia, el sistema de justicia asume que las mujeres reportadas como desaparecidas en realidad “andan por allí con el novio” o se buscaron su destino por "su estilo de vida” que las relaciona a ámbitos de dominio del narcotráfico, como bares y burdeles. Por esta razón es casi imposible que se siga la pista de la esclavitud y violencia sexual e intrafamiliar en el espacio público y privado (Monárrez Fragoso, 2009).

Los estudios sobre la esclavitud con fines de explotación sexual comercial han evidenciado que los tratantes “enganchan” a sus víctimas convirtiéndose primero en novios devotos; o, bien, son los padres, madres y hermanos que se parapetan en reglas paralegales o tradicionales para prostituirlas, venderlas o hacerlas esclavas sexuales personales. Luego las jovencitas sólo “desaparecen”. Por ejemplo, según un estudio sobre proxenetas en las comunidades nahuas de Tlaxcala (Romero Malgarejo y Pech Matamoros, 2014), los hombres se dedican a prostituir mujeres desde 1960, y tienen una especie de “escuela” en la que los padrotes enseñan a los jóvenes a vestirse y hablar para enamorar a mujeres jóvenes de Oaxaca y Puebla, que trabajan en la Ciudad de México, en el sector de cuidados y servicio doméstico, para forzarlas a prostituirse. Mientras que son trasladadas contra su voluntad por una amplia red de proxenetas tlaxcaltecas en Ciudad de México, Guadalajara, Coatzacoalcos, Matamoros, Tampico, Tijuana, Tlaxcala y Apizaco, en México; y Nueva 
York, Chicago y Houston, en Estados Unidos, en sus casas simplemente “desaparecen” (Romero Malgarejo y Pech Matamoros, 2014).

Para llegar a despojarlas de sus cuerpos las hacen sus novias, se casan e incluso tienen hijos con ellas para persuadirlas de no escapar. Para someterlas, las golpean brutalmente a ellas y a sus hijos, llegando incluso a matarlos con tal de mantenerlas en la esclavitud (Romero Malgarejo y Pech Matamoros, 2014). Mientras esto les ocurre, para sus familias simplemente desaparecieron: no se vuelve a saber de ellas. En el contexto de desaparición forzada sistemática en el país, se puede suponer que fueron desaparecidas de la forma en que fueron desaparecidos los hombres.

\section{Masacre y feminicidio}

El asesinato del enemigo, e incluso el asesinato indiscriminado de la población civil, no es raro en las guerras y ciertamente es común en las nuevas guerras, y en las guerras necropolíticas. Como ya se dijo en la primera parte de este capítulo, el número de muertes de la narcoguerra en México asciende ya a 150,000, de las cuales la mayoría corresponde a hombres. Pero no es el uso del asesinato lo que distingue a las guerras necropolíticas. Lo que las diferencia es el uso intensivo de la masacre, que es una tecnología necropolítica por excelencia. Mientras que en las guerras tradicionales el campo de concentración era central para la administración de la vida y la muerte, en la necropolítica las tecnologías son más móviles, como la masacre (Mbembe, 2011).

En México, de 2006 a 2015 se pueden contar por lo menos 13 masacres de las que se tiene conocimiento a través de los medios, conteo que no excluye que haya habido otras. De hecho, la existencia de 201 fosas clandestinas (2006-2015) sugiere que las desapariciones pudieran ser el resultado de asesinatos y masacres varias (Open Society, 2016). Entre las masacres conocidas, se encuentran las perpetradas en La Marquesa, Estado de México (2008): 24 albañiles fueron secuestrados y asesinados por presuntos miembros de La 
Familia Michoacana; Acapulco, Guerrero (2010): un comando armado secuestró a 22 turistas michoacanos, de los cuales 18 aparecieron muertos días después; Villas de Salvárcar, Ciudad Juárez, Chihuahua (2010): presuntos sicarios dispararon contra 60 estudiantes de entre 12 y 15 años, matando a 16 e hiriendo a 12; Guadalajara, Jalisco (2011): presuntos narcos dejaron los cuerpos de 26 personas en el monumento Arcos del Milenio a unos cuantos días de que comenzaran en esa ciudad los Juegos Panamericanos; Allende, Coahuila (2011): el Ejército irrumpió en las casas del pueblo, quemó los negocios y secuestró a 300 personas que siguen desaparecidas hasta la fecha; San Fernando, Tamaulipas (2011): 72 migrantes fueron asesinados a manos de Los Zetas por negarse a trabajar como sicarios.

Asimismo, están las masacres cometidas en: Monterrey, Nuevo León (2011): presuntos miembros de Los Zetas irrumpieron e incendiaron un casino donde acribillaron al dueño por no pagar cuota y mataron a 52 personas con el incendio; Cadereyta, Nuevo León (2014): 49 torsos fueron tirados a lo largo de una carretera; Ayotzinapa, Guerrero (2014): secuestro y desaparición forzada de 43 estudiantes a manos de policías y militares; y Tlatlaya, Estado de México (2014): el Ejército ejecutó a 22 presuntos delincuentes que se habían rendido después de ser acorralados; Tahuato, Michoacán (2015): la Policía Federal ejecutó también a 42 civiles presuntamente criminales que ya se habían rendido; Apatzingán, Michoacán (2015): policías y militares dispararon contra grupos de autodefensa matando a 16 e hiriendo a 44; Zitlala, Guerrero (2015): un comando armado asesinó a siete personas de esa comunidad indígena; y Monterrey, Nuevo León (2016): reos del penal de Topo Chico se enfrentaron en una cruenta riña que dejó un saldo de 49 muertos.

Por otra parte, el feminicidio puesto de forma simple es el "asesinato misógino de mujeres cometido por hombres; es una forma de violencia sexual” (Radford, 2006, p. 33). Sin embargo, lo que define mejor el feminicidio para explicar el caso mexicano es la idea de feminicidio sexual sistémico, de Julia Monárrez (2009), el cual “abarca o pertenece a la totalidad de un sistema donde coinciden los elementos culturales, políticos, económicos y religiosos que confluyen para que se dé el feminicidio” (Monárrez Fragoso, 2009, p. 12). 
Estos elementos abarcan la clase social, "el color de piel, la hegemonía de la violencia patriarcal, capitalista y las ilegalidades” (Monárrez Fragoso, 2009, p. 27).

El feminicidio se usa como se usaron los campos de exterminio para implementar la solución final a la cuestión judía. Foucault dijo que los campos de exterminio fueron las tecnologías biopolíticas más sofisticadas que usaron los nazis para dejar y hacer morir a los judíos que no tenían utilidad como fuerza de trabajo o científica: mujeres niños y niñas, ancianos/as. En la guerra por desposesión necropolítica de cuerpos femeninos, la tecnología principal es el feminicidio. Como en la masacre, no hay intención de exterminio, pero se hace o se deja morir a aquellas mujeres que no son útiles ya, por resistirse a la esclavitud sexual con fines comerciales o de dominación y a la autoafirmación endriaga.

Esto se debe que los sujetos endriagos no sólo buscan reconocimiento y enriquecimiento. También buscan autoafirmarse imponiendo su control sobre su mujer, sus hijos y su casa. El endriago puede asesinar a su pareja o sus hijas/os o pagar por ello si descubre que se están saliendo de su ámbito de dominio privado. Se les domina para violarlas, controlar su fertilidad, sexualidad y autonomía económica, y abusar impunemente de las hijas y los hijos. Hay mujeres que acceden a los términos de los endriagos para resguardar su vida y la de sus hijos o simplemente para no quedarse solas porque han sido convencidas de que valen tan poco que sólo él (el endriago), las ama (Cacho, 2010).

\section{Conclusión}

El artículo criticó los reportes de derechos humanos porque ignoran las continuidades de género que hay en la violencia criminal que origina la crisis de derechos humanos que vivimos. Con base en una gran variedad de datos estadísticos sobre desplazamiento y migración forzada, violencia contra las mujeres y victimización, se evidenció que las mujeres sufren violencia sexual y doméstica que en muchas ocasiones es una continuidad de la violencia criminal, sólo que no está apropiadamente registrada. Luego se desarrolla la 
idea de las guerras necropolíticas como un tipo de conflicto que simultáneamente explica la violencia delincuencial y la de género como parte de un contínuum de una violencia cuyo objetivo es asegurar el comercio de la droga y la mercantilización los cuerpos de las mujeres para afirmar los mercados criminales.

Como se sabe que la narcoguerra y la violencia de género no persiguen los mismos objetivos, se hizo una tipología de guerras necropolíticas, que incluye dos: la guerra por la gubernamentalización necropolítica del Estado y la guerra por la desposesión de los cuerpos de las mujeres. Mientras que una tiene que cooptar y reconfigurar al Estado, la otra se propone desposeer a las mujeres de sus cuerpos. Pero comparten una característica: un espacio socio-legal disfuncional, permanentemente corrupto y deliberadamente letal, que asegura la impunidad de las tecnologías de muerte del necropoder: masacre, feminicidio y desaparición forzada.

La masacre y la desaparición forzada son las tecnologías preferidas del necropoder para administrar muerte en el ámbito de la guerra por la gubernamentalización necropolítica del Estado. La desaparición es una tecnología necropolítica usada sobre niñas y mujeres jóvenes (de 0 a 30 años) para extraer sus cuerpos y someterlos a esclavitud sexual, y el feminicidio es la tecnología necropolítica usada en mujeres de más de 30 años cuyos cuerpos no tienen utilidad comercial, o cuando se han revelado contra la dominación económica, sexual, emocional o física dentro del hogar y la esclavitud sexual. Todo es posible por la impunidad que impera para los delitos en general y los delitos sexuales en particular.

\section{Referencias bibliográficas}

Auyero, J. (2007). Routine politics and violence in Argentina: the gray zone of state power, Cambridge studies in contentious politics. New York: Cambridge University Press.

Bunker, R. J. (11 de septiembre de 2011). Criminal (Cartel \& Gang) Insurgencies in Mexico and the Americas: What you need to know, not what you want to hear. Small Wars Journal. Recuperado de http://archives.republicans.foreignaffairs.house.gov/112/bun091311.pdf 
Butler, J y Athanasiou, A. (2013). Dispossession: the performative in the political. Cambridge: Polity Press.

Cacho, L. (2010). Esclavas del poder: un viaje al corazón de la trata sexual de mujeres y niñas en el mundo. Madrid: Debate.

Comisión Ejecutiva de Atención a Víctimas. (2016). Resultados preliminares del Diagnóstico sobre la atención de la violencia sexual en México- resumen ejecutivo. México: Comisión Ejecutiva de Atención a Víctimas. Recuperado de https://www.gob.mx/cms/uploads/attachment/file/118490/Resumen_Ejecutivo_diagn o_stico_violencia_Sexual_CEAV.pdf

Chinkin, C. (1999). A Critique of the public/private dimension. European Journal of International Law, 10, 387-395.

Comisión Interamericana de Derechos Humanos. (2015). Situación de los derechos humanos en México. México: Comisión Interamericana de los Derechos Humanos.

Comisión Mexicana de Defensa y Promoción de los Derechos Humanos A.C. (2014). Desplazamiento interno forzado en México. México: Comisión Mexicana de Defensa y Promoción de los Derechos Humanos.

Comisión Nacional de Derechos Humanos. (2016). Informe Especial sobre Desplazamiento Forzado Interno (DFI) en México. México: Comisión Nacional de Derechos Humanos.

Equipo Bourbaki. (2011). Reflexiones sobre la guerra en México. Un lector del Informe Bourbaki. México. Recuperado de https://issuu.com/mxlapazmx/docs/resumeninformebourbaki

Flores, C. A. (2012). La lógica del botín: de la cooptación del estado y el estado “fallido”. Arenas. Revista Sinaloense de Ciencias Sociales, 13 (1), 11-44. (2013). Historias de polvo y sangre: génesis y evolución del tráfico de drogas en el estado de Tamaulipas. México: CIESAS.

Foucault, M. (1997). The Essential Works of Michel Foucault: 1954-1984. Vol. I, Ethics: Subjectivity and Truth. New York: The New Press New York.

Gal, S. (2005). Language Ideologies Compared: Metaphors of Public/Private. Journal of Linguistic Anthropology, 15(1), 23-37. 
Harvey, D. (2004). El “nuevo” imperialismo: acumulación por desposesión. Socialist register 2004, 99-129.

Internal Displacement Monitoring Centre. (2015). Global Overview 2015. People internally displaced by conflict and violence. Geneva: Internal Displacement Monitoring Centre/Norwegian Refugee Council.

Instituto Nacional de Estadística y Geografía. (2013). Panorama de violencia contra las mujeres en México. México: Instituto Nacional de Estadística y Geografía.

Instituto Nacional de Estadística y Geografía. (2015). Encuesta Nacional de Victimización y Percepción sobre Seguridad Pública (ENVIPE) 2015. México: Instituto Nacional de Geografía y Estadística.

Kaldor, M. (2006). New and Old Wars: Organized Violence in a Global Era (2nd ed.). Stanford University Press.

Le Clercq, J. A. y Rodríguez Sánchez-Lara, G. (Coords.), (2016). IGI-MEX. Índice Global de impunidad México 2016. Cholula, Puebla: Universidad de las Américas, Puebla, Consejo Ciudadano de Seguridad y Justicia de Puebla y Centro de Estudios sobre Impunidad y Justicia UDLAP.

Mbembe, A. (2011). Necropolítica. España: Melusina.

Merino, J., Zarkin, J., y Fierro, E. (1 de enero de 2015). Desaparecidos. Nexos. Recuperado de http://www.nexos.com.mx/?p=23811

Monárrez Fragoso, J.L. (2009). Trama de una injusticia. Feminicidio sexual sistémico en Ciudad Juárez. Tijuana: Estudios de Género, Colegio de la Frontera Norte, Porrúa.

Open Society Justice Initiative. (2016). Atrocidades innegables. Confrontando crímenes de lesa humanidad en México. Nueva York: Open Society Foundations.

Organización de las Naciones Unidas. (1998). Estatuto de Roma de la Corte Penal Internacional. Roma: Corte Penal Internacional.

Proceso. (20 de enero de 2016). Menores de edad, 30\% de los desaparecidos en México: ONU. Proceso. Recuperado de: http://www.proceso.com.mx/427091

Radford, J. (2006). Introducción. En D. E. Russell y J. Radford (Eds.), Feminicidio. La política del asesinato de las mujeres (33-52). México: CEIICH-UNAM, Cámara de Diputados. 
Romero, O., y Pech, A. (2014). La violencia de los proxenetas en la prostitución de mujeres en la historia regional de los nahuas de la Malinche. En R. Romano, O. Romero y R. Jiménez (Coords.), Escenarios, realidades, e imaginarios en tiempos violentos. Violencia, actores y enemigos del Estado (pp. 9-115). Tlaxcala: Universidad Autónoma de Tlaxcala.

Rubio Díaz-Leal, L. (2014). Desplazamiento interno inducido por la violencia: una experiencia global, una realidad mexicana. México: ITAM, CMDPDH.

Schneider, J., y Schneider, P. (2003). Reversible destiny: mafia, antimafia, and the struggle for Palermo. Berkeley: University of California Press.

Segato, R. L. (2006). La escritura en el cuerpo de las mujeres asesinadas en Ciudad Juárez. Territorio, soberanía y crímenes de segundo estado. Buenos Aires: Tinta Limón.

(2014). Las nuevas formas de la guerra y el cuerpo de las mujeres. Sociedade e Estado, 29(2), 341-371.

Sullivan, J. P. (2012). From Drug Wars to Criminal Insurgency: Mexican Cartels, Criminal Enclaves and Criminal Insurgency in Mexico and Central America. Implications for Global Security. Fondation Maison des Sciences de L'homme - Le College d'Etudes Mondiales, 9. Recuperado de https:/halshs.archives-ouvertes.fr/halshs00694083/document

United Nations High Commissioner for Refugees. (2015). Women on the run. First hand accounts of refugees fleeing El Salvador, Guatemala, Honduras, and Mexico. United Nations High Commissioner for Refugees.

(2007). Asylum Levels and Trends in Industrialized Countries, 2007. Statistical Overview of Asylum Applications Lodged in Europe and Selected NonEuropean Countries. Geneva: United Nations High Commissioner for Refugees.

(2008). Global Trends: Refugees, Asylum-seekers, Returnees, Internally Displaced and Stateless Persons. Geneva: United Nations High Commissioner for Refugees.

(2009). 2009 Global Trends: Refugees, Asylum-seekers, Returnees, Internally Displaced and Stateless Persons. Geneva: United Nations High Commissioner for Refugees. 
(2010). Asylum Levels and Trends in Industrialized Countries, 2010. Statistical Overview of Asylum Applications Lodged in Europe and Selected NonEuropean Countries. Geneva: United Nations High Commissioner for Refugees. (2011). A Year of Crises. UNHCR Global Trends 2011. Geneva: United Nations High Commissioner for Refugees.

(2012). Displacement. The New 21st Century Challenge. Geneva: United Nations High Commissioner for Refugees. (2013). UNCHR Asylum Trends 2013. Levels and Trends in Industrialized Countries. Geneva: United Nations High Commissioner for Refugees. (2014). UNCHR Asylum Trends 2014. Levels and Trends in Industrialized Countries. Geneva: United Nations High Commissioner for Refugees. (2015). UNHCR Mid-Year Trends 2015. Geneva: United Nations High Commissioner for Refugees. Valencia, S. (2010). Capitalismo Gore. España: Melusina.

\section{Sobre la autora}

Ariadna Estévez es doctora en derechos humanos por la Sussex University de Inglaterra, maestra en sociología política por la City University de Inglaterra, y licenciada en periodismo y comunicación colectiva por la Universidad nacional Autónoma de México (UNAM). Es investigadora Titular Definitiva de la UNAM-CISAN, y tutora en la Facultad de Ciencias Políticas y Sociales de la misma universidad. Entre sus intereses de investigación se incluyen la biopolítica de asilo en América del Norte, la necropolítica en México y la crítica a la teoría de derechos humanos desde una perspectiva necropolítica y feminista. Publica ampliamente en español e inglés. Es autora de (2012) Human Rights, Migration and Social Conflict. Towards a Decolonized Global Justice (PalgraveMacmillan), publicado en español en 2014 (UNAM), y de (2016) “¿Derechos humanos o ciudadanía universal?: Aproximación al debate de los derechos en la migración”, en Revista Mexicana de Sociología. 